\title{
Breathing and Math Performance: Implications for Performance and Neurotherapy
}

\author{
Erik Peper ${ }^{1}$, Shannon Lee ${ }^{1}$, Richard Harvey ${ }^{1}$, and I-Mei Lin ${ }^{2}$ \\ ${ }^{1}$ Institute for Holistic Health Studies/Department of Health Education, San Francisco State University, San Francisco, \\ California, USA \\ ${ }^{2}$ Department of Psychology, College of Humanities and Social Sciences, Kaohsiung Medical University, Taiwan
}

\begin{abstract}
This report of findings describes students' self-reported difficulty and anxiety during test taking and the effect of deliberate gasping or diaphragmatic breathing on the ability to solve math problems. During the evaluation of an experiential classroom activity, 103 university students filled out a short questionnaire about performance anxiety and blanking out when taking exams. Then, they were asked to solve math problems while either gasping or slow diaphragmatic breathing. Students reported a high frequency of blanking out (mean $=5.3$ ), difficulty during exams (mean $=6.7$ ), and difficulty with math (mean $=6.2$ ) on a scale from 1 (never) to 10 (always). The students reported significantly more difficulty in solving math problems when gasping than during slow breathing $(p<.01)$ and significantly more anxiety during gasping $(p<.01)$ than during slow breathing $(p<.01)$ when solving math problems. Most students were completely surprised how their breathing patterns affected their ability to perform a simple math test. Numerous students have reported that when they implemented this slow breathing approach at the moment they felt anxiety, their anxiety slightly decreased and they would perform better on exams. Included are comments to improve study habits, memory consolidation, and how to incorporate somatic feedback of breathing patterns into learning and training within other settings such as during neurotherapy.
\end{abstract}

Keywords: gasping; math performance; anxiety; diaphragmatic breathing; learning

Citation: Peper, E., Lee, S., Harvey, R., \& Lin, I.-M. (2016). Breathing and math performance: Implications for performance and neurotherapy. NeuroRegulation, 3(4), 142-149. http://dx.doi.org/10.15540/nr.3.4.142

*Address correspondence to: Erik Peper, PhD, Institute for Holistic Health Studies/Department of Health Education, San Francisco State University, 1600 Holloway Avenue, San Francisco, CA 94132, USA.

Email: epeper@sfsu.edu

Copyright: (c) 2016. Peper et al. This is an Open Access article distributed under the terms of the Creative Commons Attribution License (CC-BY).

Edited by:

Rex L. Cannon, PhD, Neurogifted, Boynton Beach, Florida, USA

Reviewed by:

Wesley D. Center, PhD, Liberty University, Lynchburg, Virginia, USA

Nancy L. Wigton, PhD, Grand Canyon University, Phoenix, Arizona, USA

\section{Introduction}

Students at all levels of education experience test anxiety (Cale, Fowler, \& Rempfer, 2012; Tatum, Lundervold, \& Ament, 2006). Test anxiety is a type of performance anxiety that is "the negative affect, worry, physiological arousal, and behavioral responses that accompany concern about failure or lack of competence on an exam or similar evaluative situation" (Matthews, Zeidner, \& Roberts, 2006, p. 175). Students often report blanking out on retrieving memorized information when taking an exam for which they have studied (Arnsten, Mazure, \& Sinha, 2012). And, fear and poor study habits often contribute to forgetting or inability to retrieve the material (Cassady \& Johnson, 2002; FitkovNorris \& Yeghiazarian, 2013).
Study habits can contribute to performance difficulty and observations of study behaviors suggests most students listen to music, respond to text messages, or monitor social network sites such as Facebook, Twitter, Instagram, or Pinterest while studying (David, Kim, Brickman, Ran, \& Curtis, 2015; Swingle, 2016). Other students study materials for one class and then immediately shift to materials from another class. While at home they study while sitting or lying on their bed and continue to check their cell phones (Sellgren, 2016).

At other times, students have internalized the cultural or familial beliefs that math is difficult and they do not have the aptitude for this material (e.g., your mother was also poor in math material; Cherif, 
Movahedzadeh, Adams, \& Dunning, 2013). These beliefs and dysfunctional study habits limit learning (Neal, Wood, \& Drolet, 2013). Yet, these beliefs can be transformed. For example, when students are asked to write about a past experience where they successfully coped with a challenge, they reported an increase in self-efficacy (Nelson \& Knight, 2010). And, high academic self-efficacy is correlated with lower levels of test anxiety and higher academic performance (Barrows, Dunn, \& Lloyd, 2013; Nelson \& Knight, 2010; Nie, Lau, \& Liau, 2011).

Fear or performance anxiety may cause blanking out on an exam or class presentation (Hodges, 2015; Spielberger, Anton, \& Bedell, 2015). At that moment of the demanded performance, the brain may be flooded with thoughts such as "I can't do it," or "I will fail," or "I used to know this, but...," or "What will people think?" The body responds with a defense reaction as if they were being threatened for survival. The emotional reactivity and anxiety overwhelms cognition, resulting in an automatic 'freeze' response of breath-holding or very shallow breathing. At that moment, the person blanks out (Hagenaars, Oitzl, \& Roelofs, 2014; Lin, Ji, Peper, \& Chang, 2014; Sink et al., 2013; von der Embse, Barterian, \& Segool, 2013).

In a previous report involving a class of 95 college students, $90 \%$ reported feeling stressed out during an exam that included inability to recall (59\%), experiencing a blackout (58\%), performing worse under stress than in practice $(58 \%)$, and difficulty processing information (42\%). Students who experience feeling stressed out compared to those who did not also reported higher anxiety scores and psychosomatic symptoms (Lin et al., 2014). People who reported feeling stressed out on a daily basis tend to breathe more thoracically and shallowly (e.g., shorter exhalation), have increased sympathetic activation, decreased parasympathetic activation, and decreased total heart rate variability (HRV; Lin et al., 2014; Valoriani et al., 2014).

When students engage in chest (thoracic) breathing during exams they also report feelings of tension and anxiety (Timmons, 1994) which may increase test anxiety. At times, students may appear dazed or stunned, like a 'deer in the headlights' and freeze when looking at exam questions or when attempting to respond to instructors' questions. In our evaluations of classroom activities, when we coach students to breathe slowly and diaphragmatically, they may counteract the freezing response and perform better, often retrieving what they previously had studied. Although many physiological markers such as increased heart rate and skin conductance do not directly correlate with math anxiety (Dew, Galassi, \& Galassi, 1984), higher HRV has been correlated with lower anxiety scores and with better performance (shorter times) in completing anagram tests (Holroyd, Westbrook, \& Badhorn, 1978). Increases in HRV has been associated with slower breathing and sympathetic-parasympathetic balance (Lehrer \& Gevirtz, 2014; Shaffer, McCraty, \& Zerr, 2014; Xhyheri, Manfrini, Mazzolini, Pizzi, \& Bugiardini, 2012). This evaluation of classroom activities involves reports of students' difficulty and anxiety during test taking and the effect of deliberate gasping to simulate a freezing response or diaphragmatic breathing to simulate a calming response when solving a math problem.

\section{Method}

\section{Subjects}

The report evaluated a classroom activity related to breathing. Whereas the information in this report was anonymous the class room roster included 103 university students; average age 24 years $(S D=7.1$ years). As an evaluation of a classroom activity, this report of findings was exempted from Institutional Review Board oversight.

Procedure

While sitting in a classroom, students filled out a short questionnaire rating their level of experiencing performance difficulty, anxiety, and blanking out when taking exams. Then they were taught and practiced the following two different breathing patterns (gasping or slow breathing) when they heard the onset of a question.

\section{Gasping when hearing onset of the question.}

The moment you hear the beginning of the question, gasp as if shocked or surprised. React just as quickly and automatically as if seeing a car racing towards you. At that moment, you do not think, you don't spend time identifying the car or look at who is driving. You reflexively and automatically jump back to the curb.

Let's practice. Remember the moment you hear the onset of my voice asking the question, "What day was it yesterday?" gasp as if startled or afraid.

During the first few practices, many students waited until they have heard the whole phrase before they gasp. The teacher then explains:

If you reacted like that waiting till the end to gasp, it would be similar to seeing a car approaching you 
and just staying in place instead of jumping out of the way.

The practice was repeated until the gasping, freezing response becomes more automatic.

\section{Slow breathing when hearing the onset of the} question.

The moment you hear the beginning of the question which you are to answer, breathe slowly inward and then exhale slowly. During the first few practices, many students waited till they have heard the whole phrase until they breathe slowly. Again, start breathing the moment you hear the onset of the question.

The practice is repeated until it became more automatic. After students have practiced and role rehearsed the two different breathing patterns, the students sitting in the left side of the classroom were asked to gasp while the students sitting in the right side of the class room were asked to take a slow diaphragmatic breath when they heard the onset of the math question such as "Subtract 7 from 93." Then they were asked to breathe in the opposite pattern, and a similar math question was asked.

When finished, they rated the difficulty in solving the math problem from 1 (easy) to 10 (impossible) as well as their levels of anxiety while performing the math problem from 1 (none) to 10 (severe). In addition, the breathing patterns of a few representative students were recorded to observe their breathing pattern when they performed the task.

\section{Results}

When taking exams, the students reported blanking out (mean $=5.3 ; S D=2.2$ ), difficulty during exams (mean $=6.7 ; S D=2.5)$, and difficulty with math (mean $=6.2 ; S D=2.5$ ) on a scale from 1 (never) to 10 (always) as shown in Figure 1.

\section{Students' Self-Assessment}

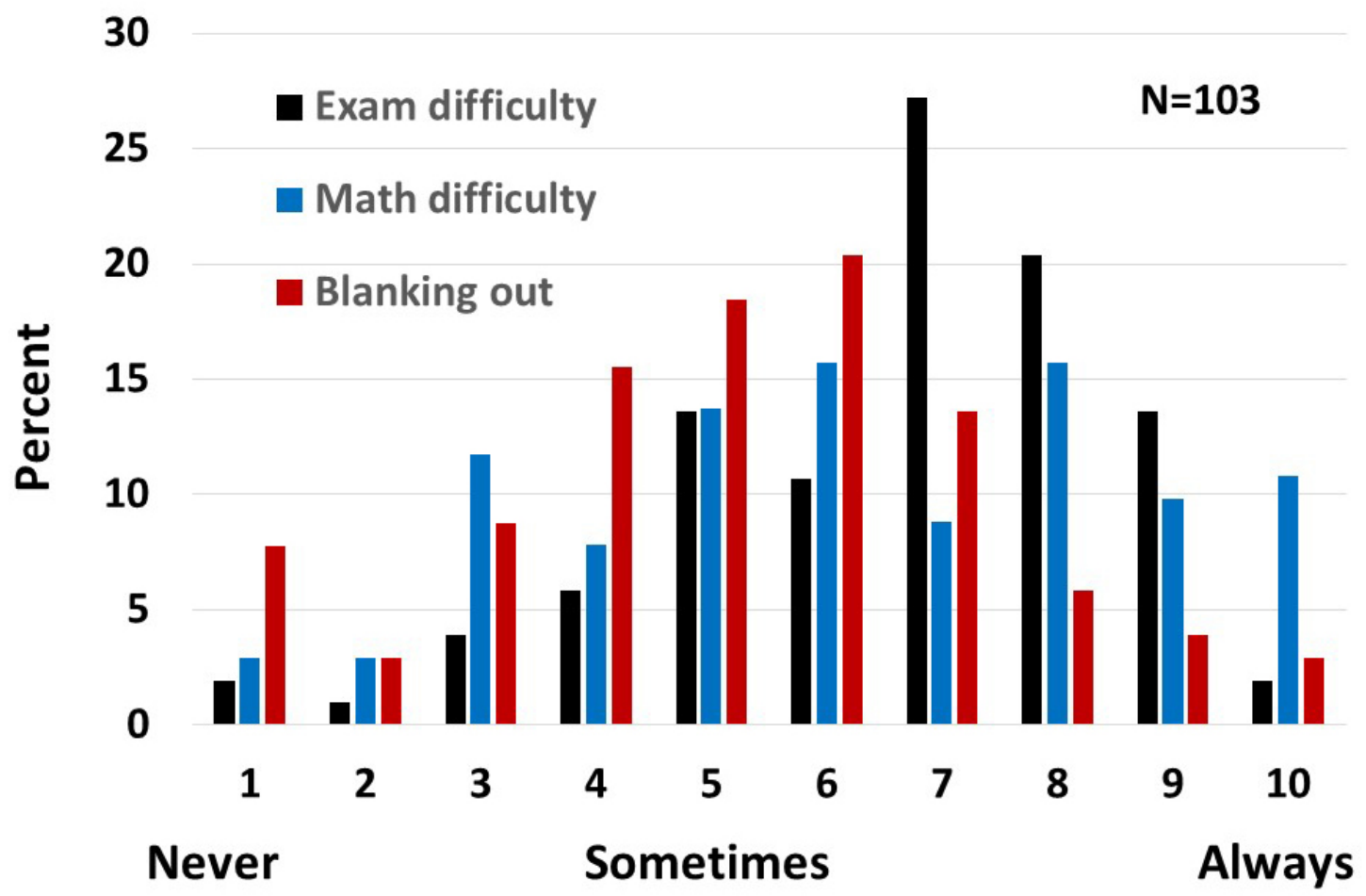

Figure 1. Self-reported difficulty in taking exams, math and blanking out. 
The students reported more difficulty in solving math problems $(p<.01)$ when gasping (mean $=6.2)$ than during slow breathing (mean $=4.9$ ) and an increase in self-assessed anxiety $(p<.01)$ during gasping
$($ mean $=5.2)$ than during slow breathing $($ mean $=$ 4.0) when solving the math problem as shown in

Figure 2.

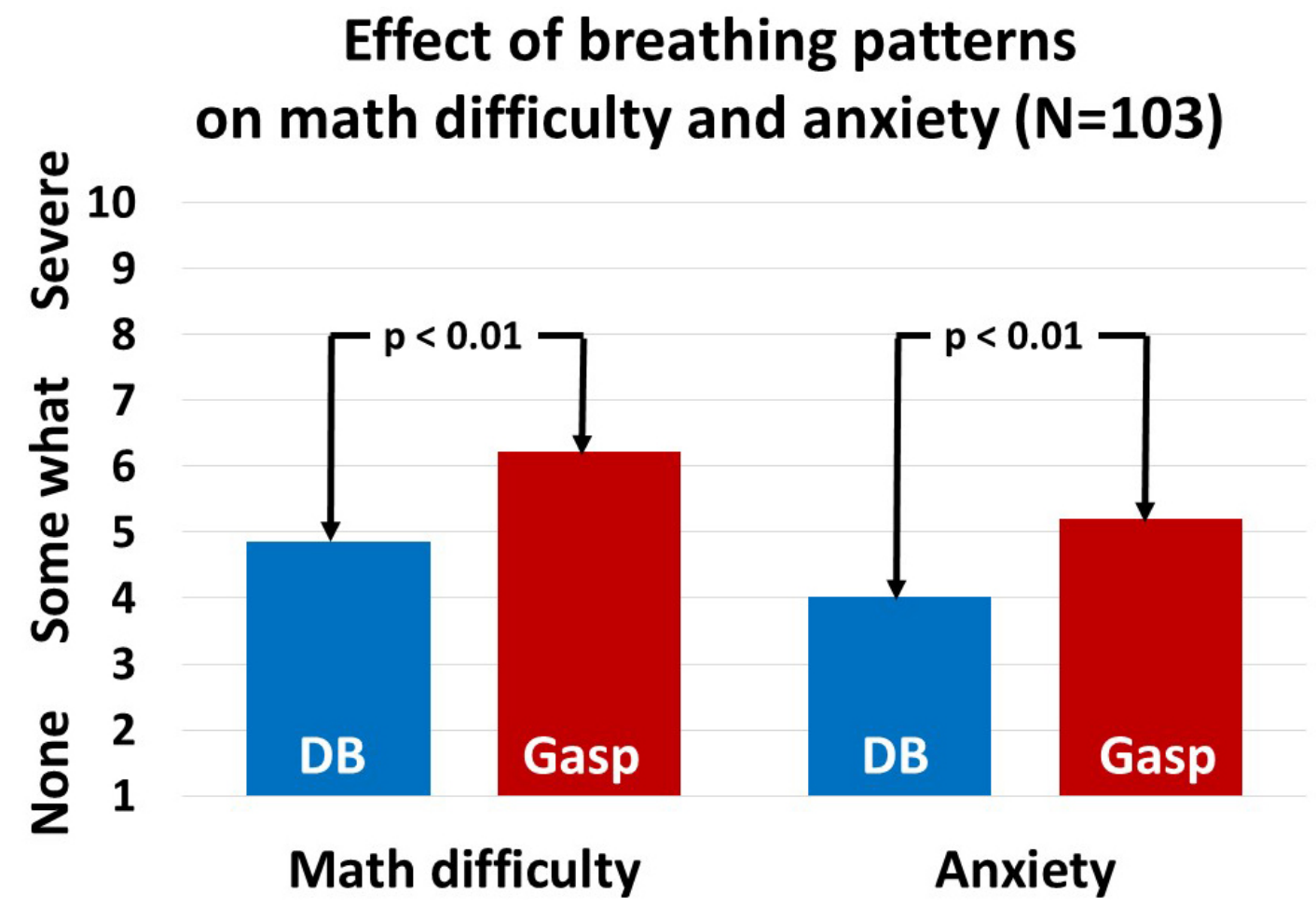

Figure 2. The effect of breathing style on math performance. Diaphragmatic breathing significantly increased math performance and decreased anxiety.

The correlation analysis showed that a history of blanking out was correlated with test anxiety $(r=0.4)$ and math difficulty was high correlated with anxiety during gasping or slow diaphragmatic breathing $(r=$ $0.60)$.
During class, a few students volunteered for physiological recordings of their breathing patterns. A representative physiological recording of gasping and slow diaphragmatic breathing at the onset of hearing the math problem is shown in Figures 3 and 4. 


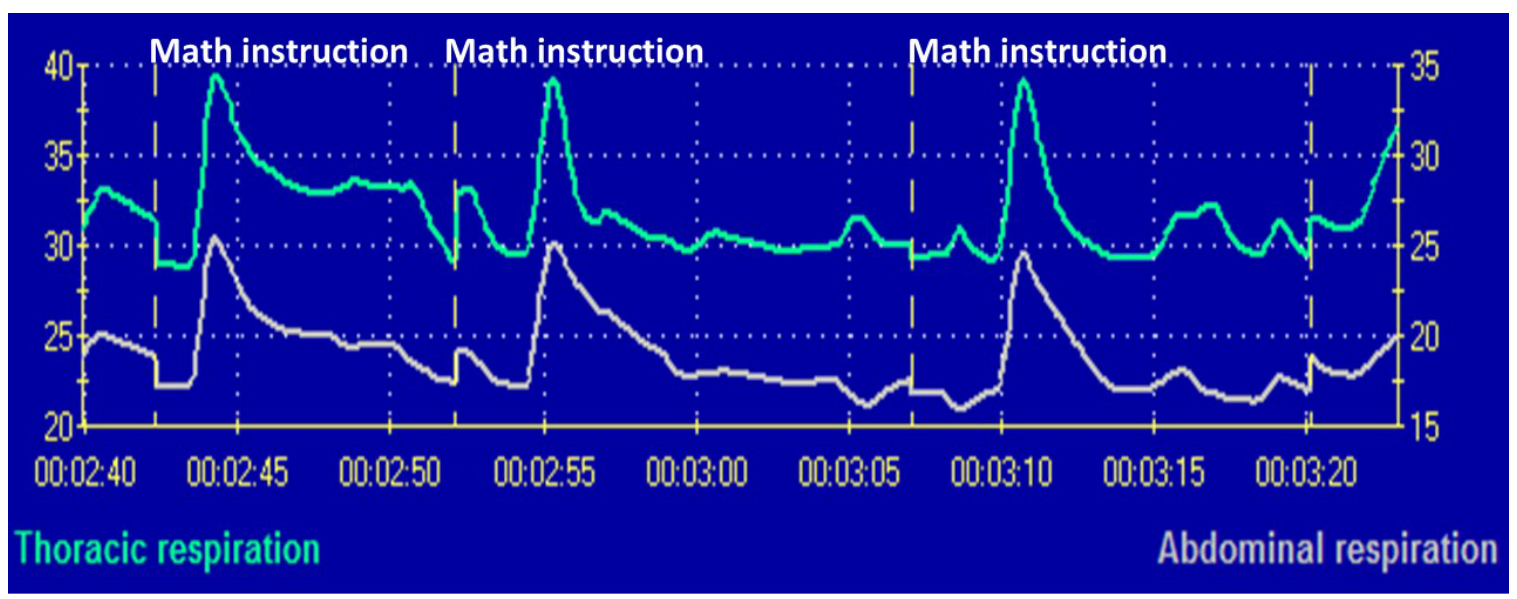

Figure 3. Representative thoracic and abdominal respiration trace as the participant gasps when hearing the onset of the math problem.

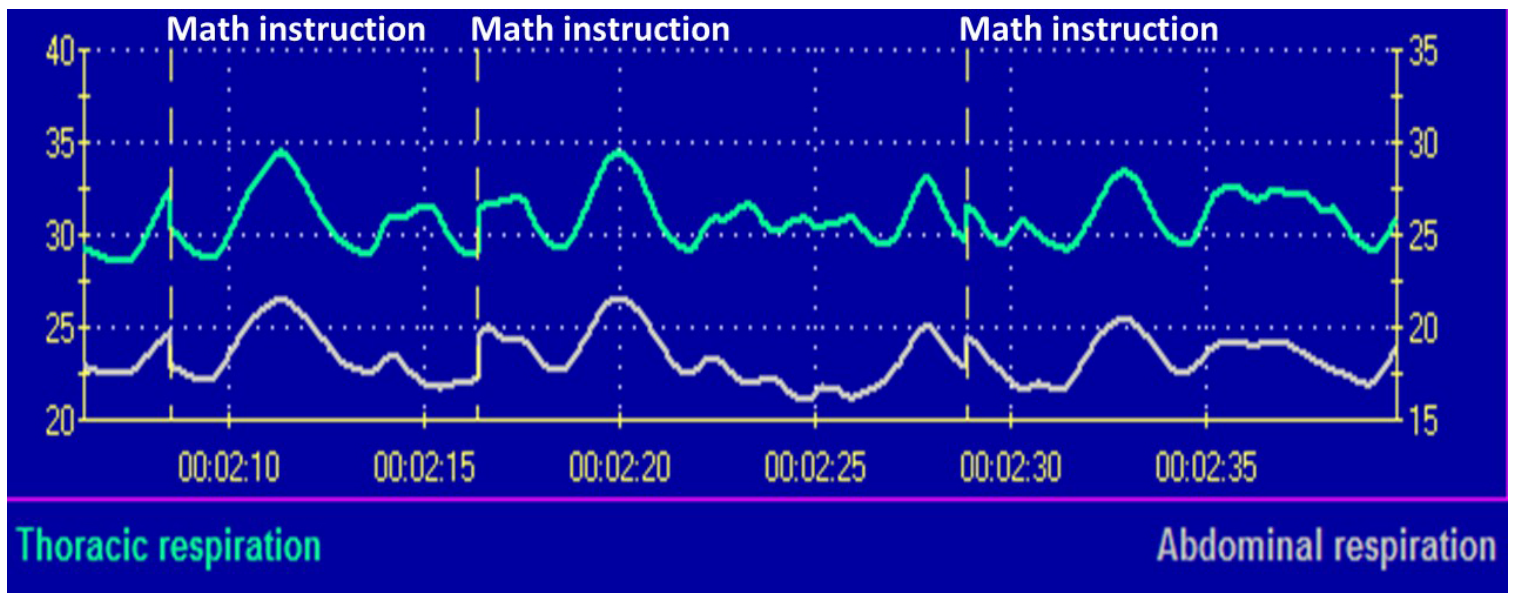

Figure 4. Representative thoracic and abdominal respiration trace as the participant breaths slower when hearing the onset of the math problem.

\section{Discussion}

Many students were totally surprised how their breathing patterns affected their ability to perform a simple math test. Some reported that they completely "blanked out" and could not perform the simple math calculation. Simulating a gasping condition as compared to slow diaphragmatic breathing condition is a useful experiential exercise to demonstrate that breathing patterns can significantly affect performance and anxiety. As one 20-year-old college student said, "When I gasped, my mind went blank and I could not do the subtraction. When I breathed slowly, I had no problem doing the subtractions. I never realized that breathing had such a big effect upon my performance."
The physiological recordings from class volunteers showed that some students did not totally master slow diaphragmatic breathing. Nevertheless, by inhibiting gasping and breathing more diaphragmatically, they improved their performance. The change in performance is most likely due to the change in breathing patterns and not to different focus of attention, since in both conditions the students had to attend to their breathing pattern. Most likely, a gasping pattern of breathing triggered the defense reaction which activated the sympathetic-adrenal system which in turn triggered the fight/flight response and reduced cognitive functioning (Porges, 2009).

Guiding students through this classroom exercise not only showed how a gasping breathing pattern 
made them perform worse but also increased anxiety. More importantly, the students learned an intervention to counter the automatic effects of gasping and anxiety by substituting slow diaphragmatic breathing for gasping. Anecdotally, students have reported that when they implemented this slow breathing approach at the moment they felt anxiety, their anxiety slightly decreased and they performed better on exams. Thus, when you are stressed and blank out during exams, taking a slow diaphragmatic breath may improve performance.

To improve performance on exams, it is also useful to condition a slow breathing with learning the material. For example, students can implement a ritual of taking three slow breaths when they begin to study and whenever they focus on new material. Then, when they take the exam and do not remember, or are anxious, they perform the same ritual of slow breathing to allow easier retrieval from memory. Obviously, this ritualistic breathconditioning approach is only useful if the students have studied the course materials effectively (suggestions for how to study effectively, see Peper, 2016). By taking charge of study habits and practicing slower breathing during studying and test taking, students reported that they experienced significant improvements in learning, remembering, accessing, and processing information.

\section{Potential Application During Neurofeedback Therapy}

Breathing patterns can significantly affect cognitive functioning and should be accounted for in neurofeedback therapy. Researchers have reported that neurofeedback improved cognitive functioning among children and have found large effect sizes for inattention and impulsivity and medium effect sizes for hyperactivity (Arns, Heinrich, \& Strehl, 2014); however, neurofeedback usually requires 30 to 40 sessions or more to achieve success (Arns, Heinrich, \& Strehl, 2014). It is possible that respiratory dysfunction such as breath-holding, slight gasping, or hyperventilation (the patterns associated with a fear/freeze reaction) contributes to lowering cognitive performance because gasping or hyperventilation is associated with an increase in theta electroencephalography (EEG) and a decrease in cortical blood flow (Fried, 1986; Konishi, 1987). Given that breathing affects the EEG, we recommend first to normalize and improve respiratory patterns, then observe whether breathing practice improves behavior and performance before beginning 30 to 40 sessions of neurofeedack training.

\section{Training in Breath Awareness}

The general breathing training consists of observing the dysfunctional breathing pattern, having the participant exaggerate the dysfunctional pattern (e.g., gasping) to experience if "freezing" evokes the symptom. Then, teach the "healthy breathing" response pattern that does not evoke the symptom. After mastering the healthy breathing response, it is recommended to teach the participant to become aware of the dysfunctional breathing pattern, interrupt the dysfunctional pattern, and substitute the functional pattern. The purpose is to facilitate selfcontrol and mastery which increases hope and shifts illness beliefs. The mechanism is similar to that of cognitive therapy for treatment of depression where the participant learns to identify dysfunction thought patterns. It also provides a "biological" model of how their symptoms are generated (e.g., the triggering of the alarm reaction shift blood flow) and how to take control. We use the following sequence to teach breath awareness.

Observe the pattern. The therapist observes the physiological recordings and somatic patterns of the participant when he/she performs a task (e.g., math subtraction).

Identify the dysfunctional pattern. The dysfunctional anticipatory patterns and response patterns are identified such as a 1 or $2 \mu \mathrm{V}$ increase in trapezius surface electromyography tension, subtle gasping, or breath holding, looking away, or slouching, or collapsing in defeat.

Exaggerate the dysfunctional pattern. The participant practices and performs the extreme exaggeration of the dysfunctional pattern. After mastery, have the participant perform the exaggerated pattern at the same time he/she performs the task (e.g., subtraction). In most cases, their cognitive performance decreases or their symptoms increase. If the symptom is aggravated, point out that this covert dysfunctional body pattern contributes to increasing the symptom. Thus, if they can become aware of this pattern, anticipate when it would occur, and substitute a healthy pattern, then they may be able to reduce their dysfunction.

Teach a functional pattern. Awareness of the dysfunctional pattern often increases anxiety and symptoms. Thus, the participant also needs to be taught an alternative health-promoting pattern. Have them practice the health-promoting pattern such as effortless breathing. Then ask them to perform the task while performing the healthpromoting pattern. In many cases, they observe that 
they can do the task significantly better or their symptoms are reduced. Repeat the same process with their exaggerated dysfunctional pattern.

Teach how to implement the new pattern into daily activities at home and at work. If they experience a difference in performance or symptoms, teach them to become aware during the day of situations that would trigger the dysfunctional pattern and substitute the functional pattern. Each time they catch themselves that their body has responded in this dysfunctional pattern, they interrupt the pattern and substitute the newly learned functional pattern.

\section{Conclusion}

Teaching awareness of covert dysfunctional patterns (e.g., gasping breath) and substituting functional patterns (e.g., slow effortless breathing) may be the basis for a useful clinical intervention to reduce anxiety symptoms and improve health. It is similar to how Whatmore and Kohli (1968) taught patients to reduce their dysponesis (misdirected muscle efforts) and demonstrated significant improvement across numerous disorders ranging from depression or hypertension to chronic pain. Similarly, Stroebel (1983) developed the quieting reflex and demonstrated significant improvement for primary Raynaud's disease, classic migraines, and common migraines after a 2-year follow-up (Ford, 1983). While Dahl, Brorson, and Melin (1992) showed significant reduction in seizures at the 8-year followup in children with refractory epileptic seizures.

This report of findings from an evaluation of a classroom activity has some limitations. For example, even though the data was analyzed in a systematic fashion, the findings may not be considered research because the report may not be generalizable beyond the evaluation of a classroom activity. The report is intended to serve as a description of activities that may be further investigated in various research settings where other tools such as random assignment to groups would be employed to extend knowledge beyond a crosssectional snapshot of a classroom activity.

When participants learn functional health-promoting skills and apply this into their daily lives, their health and performance improves. Thus, when students take charge of their study habits and practice slower breathing during studying and test taking as compared to gasping or breath holding, they may experience improvements in learning, remembering, accessing, and processing information. We recommend that these slow breathing skills are taught to improve health and productivity.

\section{Author Note}

Adapted from: Lee, S., Sanchez, J., Peper, E., \& Harvey, R. (2016, March). Effect of breathing style on math problem solving. Poster session presented at the 47th Annual Meeting of the Association for Applied Psychophysiology and Biofeedback, Seattle, WA.

\section{References}

Arns, M., Heinrich, H., \& Strehl, U. (2014). Evaluation of neurofeedback in ADHD: The long and winding road. Biological Psychology, 95, 108-115. http://dx.doi.org/10.1016 /j.biopsycho.2013.11.013

Arnsten, A., Mazure, C. M., \& Sinha, R. (2012). This is your brain in meltdown. Scientific American, 306(4), 48-53. http://dx.doi.org/10.1038/scientificamerican0412-48

Barrows, J., Dunn, S., \& Lloyd, C. A. (2013). Anxiety, self-efficacy, and college exam grades. Universal Journal of Educational Research, 1(3), 204-208. http://dx.doi.org/10.13189 lujer.2013.010310

Cale, N., Fowler, C., \& Rempfer, M. (2012). Test anxiety and learning potential in college students. Undergraduate Research Journal for the Human Sciences, 11(1), 1-5.

Cassady, J. C., \& Johnson, R. E. (2002). Cognitive test anxiety and academic performance. Contemporary Educational Psychology, 27(2), 270-295. http://dx.doi.org/10.1006 /ceps.2001.1094

Cherif, A. H., Movahedzadeh, F., Adams, G. E., \& Dunning, J. (2013). Why do students fail? Students' Perspective. In $A$ Collection of Papers on Self-Study and Institutional Improvement, pp. 35-51. Chicago, IL: The Higher Learning Commission.

Dahl, J., Brorson, L.-O., \& Melin, L. (1992). Effects of a broadspectrum behavioral medicine treatment program on children with refractory epileptic seizures: An 8-year follow-up. Epilepsia, 33(1), 98-102. http://dx.doi.org/10.1111/j.15281157.1992.tb02289.x

David, P., Kim, J.-H., Brickman, J. S., Ran, W., \& Curtis, C. M. (2015). Mobile phone distraction while studying. New Media \& Society, 17(10), 1661-1679. http://dx.doi.org/10.1177 $/ 1461444814531692$

Dew, K. H., Galassi, J. P., \& Galassi, M. D. (1984). Math anxiety: Relation with situational test anxiety, performance, physiological arousal, and math avoidance behavior. Journal of Counseling Psychology, 31(4), 580-583. http://dx.doi.org /10.1037/0022-0167.31.4.580

Fitkov-Norris, E. D., \& Yeghiazarian, A. (2013). Measuring study habits in higher education: The way forward? Journal of Physics: Conference Series, 459(1), 1-6. http://dx.doi.org/10.1088/1742-6596/459/1/012022

Ford, C. V. (1983). The somatizing disorders: Illness as a way of life. New York, NY: Elsevier Science Ltd.

Fried, R. (1987). The hyperventilation syndrome: Research and clinical treatment. Baltimore, MD: John Hopkins University Press.

Hagenaars, M. A., Oitzl, M., \& Roelofs, K. (2014). Updating freeze: Aligning animal and human research. Neuroscience \& Biobehavioral Reviews, 47, 165-176. http://dx.doi.org /10.1016/j.neubiorev.2014.07.021

Hodges, W. F. (2015). The psychophysiology of anxiety. In M. Zuckerman \& C. D. Spielberger (Eds.), Emotions and Anxiety (PLE: Emotion): New Concepts, Methods, and Applications (pp. 175-194). New York: Psychology Press. 
Holroyd, K. A., Westbrook, T., Wolf, M., \& Badhorn, E. (1978). Performance, cognition, and physiological responding in test anxiety. Journal of Abnormal Psychology, 87(4), 442-451. http://dx.doi.org/10.1037/0021-843X.87.4.442

Konishi, T. (1987). The standardization of hyperventilation on EEG recording in childhood II. The quantitative analysis of build-up. Brain \& Development, 9(1), 21-25. http://dx.doi.org /10.1016/S0387-7604(87)80005-0

Lee, S., Sanchez, J., Peper, E., \& Harvey, R. (2016, March). Effect of breathing style on math problem solving. Poster session presented at the 47th Annual Meeting of the Association for Applied Psychophysiology and Biofeedback, Seattle WA.

Lehrer, P. M., \& Gevirtz, R. (2014). Heart rate variability biofeedback: How and why does it work? Frontiers in Psychology, 5(756), 1-9. http://dx.doi.org/10.3389 /fpsyg.2014.00756

Lin, I.-M., Ji, H.-J., Peper, E., \& Chang, C.-F. (2014). Deer in headlights: The relationships between brain empty syndrome under stress and psychophysiological responses. The Journal of Kaohsiung Behavioral Sciences, 4, 115-140.

Matthews, G., Zeidner, M., \& Roberts, R. D. (2006). Models of personality and affect for education: A review and synthesis. In P. A. Alexander, \& P. H. Winne (Eds.), Handbook of Educational Psychology (2nd ed., pp. 163-186). Mahwah, New Jersey: Lawrence Erlbaum Associates.

Neal, D. T., Wood, W., \& Drolet, A. (2013). How do people adhere to goals when willpower is low? The profits (and pitfalls) of strong habits. Journal of Personality and Social Psychology, 104(6), 959-975. http://dx.doi.org/10.1037/a0032626

Nelson, D. W., \& Knight, A. E. (2010). The power of positive recollections: Reducing test anxiety and enhancing college student efficacy and performance. Journal of Applied Social Psychology, 40(3), 732-745. http://dx.doi.org/10.1111/j.15591816.2010.00595.x

Nie, Y., Lau, S., \& Liau A. K. (2011). Role of academic selfefficacy in moderating the relation between task importance and test anxiety. Learning and Individual Differences, 21(6), 736-741. http://dx.doi.org/10.1016/j.lindif.2011.09.005

Peper, E. (2016, September 18). Do you blank out on exams? Improve school performance with breathing. Retrieved October 24, 2016, from https://peperperspective.com/2016/09 /18/do-you-freeze-up-breathe-and-improve-schoolperformance/

Porges, S. (2009). The polyvagal theory: New insights into adaptive reactions of the autonomic nervous system. Cleveland Clinic Journal of Medicine, 76(Suppl. 2), S86-S90. http://dx.doi.org/10.3949/ccjm.76.s2.17

Sellgren, K. (2016). Teenagers 'checking mobile phones in night.' Retrieved from http://www.bbc.com/news/education37562259

Shaffer, F., McCraty, R., \& Zerr, C. L. (2014). A healthy heart is not a metronome: An integrative review of the heart's anatomy and heart rate variability. Frontiers in Psychology, 5 , 1040. http://dx.doi.org/10.3389/fpsyg.2014.01040

Sink, K. S., Walker, D. L., Freeman, S. M., Flandreau, E. I., Ressler, K. J., \& Davis, M. (2013). Effects of continuously enhanced corticotropin releasing factor expression within the bed nucleus of the stria terminalis on conditioned and unconditioned anxiety. Molecular Psychiatry, 18(3), 308-319. http://dx.doi.org/10.1038/mp.2011.188

Spielberger, C. D., Anton, W. D., \& Bedell, J. (2015). The nature and treatment of test anxiety. In M. Zuckerman \& C. D. Spielberger (Eds.), Emotions and Anxiety: New Concepts, Methods, and Applications (pp. 317-344). New York: Psychology Press.

Stroebel, C. F. (1983). QR: The quieting reflex. Berkley Trade Pub.

Swingle, M. K. (2016). i-Minds: How cell phones, computers, gaming, and social media are changing our brains, our behavior, and the evolution of our species. Portland, OR Inkwater Press.

Tatum, T., Lundervold, D. A., \& Ament, P. (2006). Abbreviated upright behavioral relaxation training for test anxiety among college students: Initial results. International Journal of Behavioral Consultation and Therapy, 2(4), 475-480. http://dx.doi.org/10.1037/h0101001

Timmons, B. H. (1994). Breathing-related issues in therapy. In B. H. Timmons \& R. Ley (Eds.), Behavioral and Psychological Approaches to Breathing Disorders (pp. 261-292). New York: Plenum Press.

Valoriani, V., Lotti, F., Vanni, C., Noci, M.-C., Fontanarosa, N., Ferrari, G., ... Noci, I. (2014). Hatha-yoga as a psychological adjuvant for women undergoing IVF: A pilot study. European Journal of Obstetrics \& Gynecology and Reproductive Biology, 176, 158-162. http://dx.doi.org/10.1016 /j.ejogrb.2014.02.007

Von der Embse, N., Barterian, J., \& Segool, N. (2013). Test anxiety interventions for children and adolescents: A systematic review of treatment studies from 2000-2010. Psychology in the Schools, 50(1), 57-71. http://dx.doi.org /10.1002/pits.21660

Whatmore, G. B., \& Kohli, D. R. (1968). Dysponesis: A neurophysiology factor in functional disorders. Systems Research and Behavioral Science, 13(2), 102-124. http://dx.doi.org/10.1002/bs.3830130203

Xhyheri, B., Manfrini, O., Mazzolini, M., Pizzi, C., \& Bugiardini, R. (2012). Heart rate variability today. Progress in Cardiovascular Diseases, 55(3), 321-331. http://dx.doi.org /10.1016/j.pcad.2012.09.001

Received: October 6, 2016

Accepted: November 18, 2016

Published: December 8, 2016 